Research papers

\title{
Climate-driven variability in the occurrence of major floods across North America and Europe
}

\author{
Glenn A. Hodgkins ${ }^{\text {a,* }}$, Paul H. Whitfield ${ }^{\mathrm{b}}$, Donald H. Burn ${ }^{\mathrm{c}}$, Jamie Hannaford ${ }^{\mathrm{d}}$, Benjamin Renard ${ }^{\mathrm{e}}$, \\ Kerstin Stahl ${ }^{\mathrm{f}}$, Anne K. Fleig ${ }^{\mathrm{g}}$, Henrik Madsen ${ }^{\mathrm{h}}$, Luis Mediero ${ }^{\mathrm{i}}$, Johanna Korhonen ${ }^{\mathrm{j}}$, Conor Murphy ${ }^{\mathrm{k}}$ \\ Donna Wilson $^{\mathrm{g}}$
}

${ }^{a}$ U.S. Geological Survey, 196 Whitten Road, Augusta, ME 04330, United States

${ }^{\mathrm{b}}$ Environment and Climate Change Canada, 401 Burrard Street, Vancouver, BC V6C 3S5, Canada

${ }^{\mathrm{c}}$ University of Waterloo, 200 University Avenue West, Waterloo, ON N2L 3G1, Canada

${ }^{\mathrm{d}}$ Centre for Ecology and Hydrology, Maclean Building, Benson Lane, Wallingford, Oxfordshire OX10 8BB, United Kingdom

e Irstea Lyon, Hydrology-Hydraulics, 5 rue de la Doua BP32108, 69616 Villeurbanne cedex, France

${ }^{\mathrm{f}}$ Albert-Ludwigs-Universität Freiburg, Fahnenbergplatz, 79098 Freiburg, Germany

${ }^{\mathrm{g}}$ Norwegian Water Resources and Energy Directorate, P.O. Box 5091, Majorstua, 0301 Oslo, Norway

${ }^{\mathrm{h}}$ DHI, Agern Allé 5, DK-2970 Hørsholm, Denmark

${ }^{\mathrm{i}}$ Technical University of Madrid, ETSI Caminos, Canales y Puertos, c/ Profesor Aranguren, 328040 Madrid, Spain

${ }^{\mathrm{j}}$ Finnish Environment Institute, SYKE, Freshwater Centre, P.O. Box 140, 00251 Helsinki, Finland

${ }^{\mathrm{k}}$ Irish Climate Analysis and Research UnitS (ICARUS), Department of Geography, Maynooth University, Maynooth, Co. Kildare, Ireland

\section{A R T I C L E I N F O}

\section{Article history:}

Received 4 February 2017

Received in revised form 16 June 2017

Accepted 12 July 2017

Available online 14 July 2017

This manuscript was handled by A.

Bardossy, Editor-in-Chief, with the

assistance of Axel Bronstert, Associate

Editor

\section{Keywords:}

Major floods

Climate variability

Trends

AMO

PDO

\begin{abstract}
A B S T R A C T
Concern over the potential impact of anthropogenic climate change on flooding has led to a proliferation of studies examining past flood trends. Many studies have analysed annual-maximum flow trends but few have quantified changes in major (25-100 year return period) floods, i.e. those that have the greatest societal impacts. Existing major-flood studies used a limited number of very large catchments affected to varying degrees by alterations such as reservoirs and urbanisation. In the current study, trends in majorflood occurrence from 1961 to 2010 and from 1931 to 2010 were assessed using a very large dataset (>1200 gauges) of diverse catchments from North America and Europe; only minimally altered catchments were used, to focus on climate-driven changes rather than changes due to catchment alterations. Trend testing of major floods was based on counting the number of exceedances of a given flood threshold within a group of gauges. Evidence for significant trends varied between groups of gauges that were defined by catchment size, location, climate, flood threshold and period of record, indicating that generalizations about flood trends across large domains or a diversity of catchment types are ungrounded. Overall, the number of significant trends in major-flood occurrence across North America and Europe was approximately the number expected due to chance alone. Changes over time in the occurrence of major floods were dominated by multidecadal variability rather than by long-term trends. There were more than three times as many significant relationships between major-flood occurrence and the Atlantic Multidecadal Oscillation than significant long-term trends.
\end{abstract}

Published by Elsevier B.V.

\section{Introduction}

Every year river floods cause enormous damage around the world (Jonkman, 2005). Understanding historical trends and multidecadal variability in major (25-100 year return period) floods is important for informing how flood frequency may change in the future. Changes in the magnitude or frequency of major floods

\footnotetext{
* Corresponding author.

E-mail address: gahodgki@usgs.gov (G.A. Hodgkins).
}

could have profound implications for buildings in floodplains and river infrastructure such as bridges, culverts, and dams. It is vital to understand historical trends and variability to inform engineering design and safety assessment, as well as the development of appropriate flood risk management responses.

Increases in global air temperature are expected to result in more intense precipitation because of the greater water-holding capacity of a warmer atmosphere (Trenberth, 2011); increased precipitation intensity and duration may result in increased river flooding (Seneviratne et al., 2012). However, flood generating 
processes are often more complex (Seneviratne et al., 2012; Whitfield, 2012), particularly in cold regions. Other natural factors influencing the magnitude of floods include antecedent soil conditions and snowmelt runoff; changes in these factors may cause floods to decrease as well as increase. For example, reduced snow due to warmer temperatures can lower flood risk (because of decreased snowmelt runoff) or increase flood risk (because of increased effective catchment area from elevational shifts in the snowline) (Hamlet and Lettenmaier, 2007).

The frequency of 100 year floods are projected to increase in some regions during the next century due to climate change (large parts of South America, central Africa and eastern Asia); however, projections in Northern Hemisphere extratropical areas are not consistent and future flood frequency may increase or decrease depending on location and climate model (Hirabayashi et al., 2013; Arnell and Gosling, 2016). Also, changes in flooding over time can be influenced by natural variability in the ocean/atmosphere system (Kundzewicz et al., 2014).

The Intergovernmental Panel on Climate Change (IPCC) concluded (Hartmann et al., 2013) that globally there is no clear and widespread evidence of changes in flood magnitude or frequency in observed flood records. That assessment was based on collating national and regional studies employing many different methods and study periods. Moreover, many studies have not separated the effects of human catchment alterations from those of climate (Burn et al., 2012; Merz et al., 2012; Harrigan et al., 2014); alterations such as urbanisation have been shown to impact observed flood trends (Vogel et al., 2011). To be informative about climatedriven flood trends, catchments should be relatively free of confounding human influences such as land-use change, diversions, abstractions and reservoir regulation. Thus, networks of minimally altered catchments-so called reference hydrologic networks (RHNs)-have been advocated (Whitfield et al., 2012).

The anticipated influence of climate change on flooding has resulted in many national or regional studies on observed annual-maximum flow trends, particularly in North America (e.g. Peterson et al., 2013; Burn and Hag Elnur, 2002) and Europe (e.g. see the review of Hall et al., 2014 and Madsen et al., 2014; Mediero et al., 2015). Larger scale analyses are less common, although one study analysed global trends (Kundzewicz et al., 2005). The literature on flood changes is dominated by analyses of annual maxima, rather than changes in higher magnitude, lower frequency floods. Annual-maximum flow series are composed primarily of minor events. Two studies (Lindström and Bergstrom, 2004; Schmocker-Fackel and Naef, 2010) have analysed changes in 10 year floods. Nevertheless, even 10 year floods are relatively minor events.

Major floods-floods with larger return periods that typically cause the greatest damage-will not necessarily exhibit the same trends as minor events. Luce and Holden (2009) demonstrated that trends over time for different flow quantiles-at the same gaugescan be very different. By using two synthetic datasets from two generalized extreme value (GEV) distributions with different parameters (Fig. 1a) it can be demonstrated that trends in minor floods can be different than changes in major floods. Differences in any of the three GEV parameters would produce different flood distributions. A Mann-Kendall trend test on a concatenated dataset of "earlier" floods from the 1 st synthetic dataset and "later" floods from the 2nd dataset shows significantly increasing floods over time $(p=0.0126$, Fig. $1 b)$; however, the largest floods decrease (Fig. 1b). For example, the probability of exceeding a streamflow of $700 \mathrm{~m}^{3} / \mathrm{s}$ decreases from 0.034 (30-year return period) in the first half of the combined dataset to 0.006 (170-year return period) in the second half.

Flood distributions with different parameters for different periods of time are plausible with respect to floods, where the floods
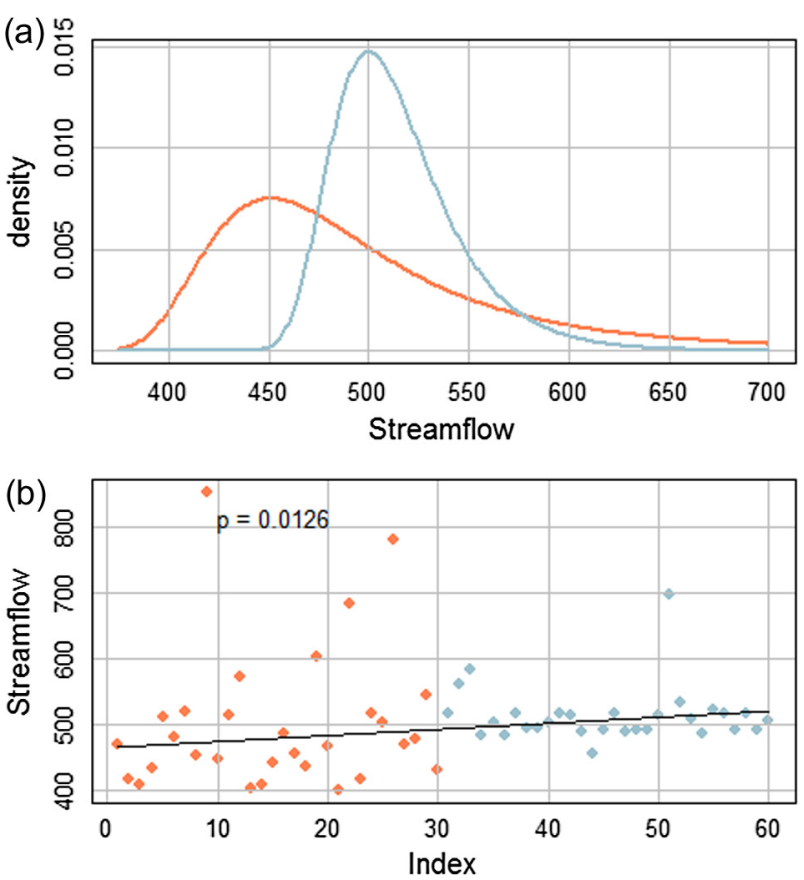

Fig. 1. (a) Probability density functions for two generalized extreme value (GEV) distributions with different parameters. The first distribution (orange) has GEV location parameter $=460$, scale $=50$, and shape $=0.2$ and the second (blue) has GEV location $=500$, scale $=30$, and shape $=0.1$. (b) Time series created by concatenating two synthetic datasets from the two distributions. The straight line shows the Sen slope whilst the p-value is from the Mann-Kendall test. (For interpretation of the references to colour in this figure legend, the reader is referred to the web version of this article.)

are generated by different processes. For example, in the northeastern United States and Atlantic Canada typical annual floods for many rivers are caused by a combination of spring snowmelt and rain, but occasionally major floods occur because of hurricane-related rainfall. If snowmelt/rain floods increased and/ or hurricane-related floods decreased, the combined flood distributions in each of the two periods would be different.

To the authors' knowledge, only two published studies have analysed trends in major (25-100 year) floods, Milly et al. (2002) and Mudelsee et al. (2003). In the former, occurrences of 100 year floods in 16 very large catchments $\left(>200,000 \mathrm{~km}^{2}\right)$ in Northern Hemisphere extratropical areas were found to have increased significantly during the 20th century ( 7 of 8 floods occurred after 1953) (Milly et al., 2002). In the latter, there was no evidence for recent increases in 100 year flood occurrence in two very large catchments $\left(54,000\right.$ and $\left.95,000 \mathrm{~km}^{2}\right)$ in central Europe (Mudelsee et al., 2003).

Multidecadal variability can affect the perceived temporal evolution of floods: what appear to be long-term trends can be due to multidecadal variability (Hannaford et al. 2013). Many authors have shown local effects of interannual climate variations on flood flows via teleconnections with the El Niño-Southern Oscillation (ENSO) and the North Atlantic Oscillation (NAO) (Lee et al., 2011; Ward et al., 2016; Shorthouse and Arnell 1999; Hannaford and Marsh, 2008; Yiou and Nogaj, 2004; Korhonen and Kuusisto, 2010). The primary modes of multidecadal variability associated with the Atlantic and Pacific Oceans are the Atlantic Multidecadal Oscillation (AMO) and the Pacific Decadal Oscillation (PDO). The AMO (Enfield et al., 2001) and the PDO (Mantua and Hare, 2002) represent variations in Atlantic Ocean and North Pacific Ocean temperatures. There has been very limited previous work at the continental scale on the relation between floods and these climatic patterns. Archfield et al. (2016) did not find more significant 
relations in the United States between flood magnitude or frequency and the AMO and PDO than would be expected due to chance.

This study presents the first intercontinental assessment of climate-driven changes over time in the occurrence of major floods (25, 50 and 100 year return periods); events of a magnitude that are likely to have the greatest societal effects. For 1204 diverse but minimally altered catchments, long-term trends are analysed as well as relations between major flood occurrence and multidecadal ocean/atmosphere variability.

\section{Data and methods}

\subsection{Data}

Detecting changes in floods attributable to changes in climate requires some rigour (Merz et al., 2012). The importance of isolating climate influences on flood trends from other influences is becoming widely recognized (Stahl et al., 2010; Wilson et al., 2010; Murphy et al., 2013; Mediero et al., 2014). In many countries, reference hydrologic networks have been designed and developed to provide good quality data and metadata from catchments without confounding land use changes, minimal hydrologic alterations such as flow regulation, and suitable long-term records (Whitfield et al., 2012; Burn et al., 2012). Many countries have developed reference hydrologic networks (Brimley et al., 1999; Bradford and Marsh, 2003; Marsh, 2010; Lins, 2012; Murphy et al., 2013; Fleig et al., 2013), whilst in others expert opinion is required to isolate this type of site. Care needs to be taken when including catchments from non-reference networks to avoid nonclimatic influences. Burn and Whitfield (2016) demonstrated that differences in flood trends exist between reference sites and other sites in Canada that have unregulated streamflow but were not designated as reference sites.

The 1204 sites considered in this study were either designated as hydrologic reference sites (970 sites) [North America: Canada, United States; Europe: France, Ireland, Norway, United Kingdom] or considered to be equivalent (234 RHN-like sites) based upon detailed review by national and local experts (Denmark, Finland, Germany, Iceland, Spain, Sweden and Switzerland). All catchments had $<10 \%$ current urban area (qualitative measure in some countries), no substantial flow alteration or known substantial land cover change, good quality peak-flow data and $<10$ years missing data. Good quality peak flow data is normally defined as being recorded at gauges where peak flows can be measured with acceptable accuracy. Peak flow data from all gauges were screened for consistency with these completeness criteria and gauges were excluded if they failed to meet them. Nested catchments ( $>30 \%$ overlap in area) were excluded except for two catchments in data-sparse regions where overlap was slightly greater. Country specific details and references are provided in Table 1 . Annualmaximum flows for each gauge were extracted from daily mean streamflow for each water year (starting in October). Gauge metadata are located in Supplementary Table 1.

It is important to acknowledge that truly pristine catchments are rare and some degree of alteration must be tolerated when working at the regional, national or continental scale. Many catchments have some human alterations but these were judged to have minimal influence on peak flows. Long-term land use change related to agriculture and forestry is generally poorly quantified and might impact major-flood trends. Some European catchments contain decentralized flood-protection measures that may have changed over time. Furthermore, although data quality is an important selection criteria, hydrometric uncertainties can never be completely ruled out; flood hydrometry is inherently challeng- ing, particularly for extreme flood flows, and large floods at many gauges are defined by indirect measurements or extrapolation of the relationship between river stage and flow. Nevertheless, these data are considered fit for purpose and represent a considerable step forward compared to past observational studies at this scale.

Because individual catchments have a small number of recorded major floods, many catchments need to be grouped to compute robust trends over time in major-flood occurrence. Gauges were grouped as follows: all study gauges; by continent; small $\left(<100 \mathrm{~km}^{2}\right)$, medium $\left(100-1000 \mathrm{~km}^{2}\right)$ and large $\left(>1000 \mathrm{~km}^{2}\right)$ catchment area; and major Köppen-Geiger climate regions (Peel et al., 2007). The widely used Köppen-Geiger climate classification includes five major climates, and is based on seasonal precipitation and temperatures. The classification does not consider flood generating processes.

The seasonality of major flood occurrences (return periods $\geq 25$ years) was computed for the 1204 study gauges for 19612010 for the major Köppen-Geiger (KG) climates (Fig. 2). Most of the gauges in this study are in KG climates $C$ (temperate) and D (cold). In North America KG climate C, major floods occurred throughout the year but were more frequent in winter (December through March had $43 \%$ of floods) and were relatively frequent in September (13\%), likely due to hurricanes and tropical storms. In North America KG climate D, spring floods dominated (April through June had $55 \%$ of floods), likely influenced by snowmelt runoff. In Europe KG climate C, winter floods were most frequent (December through February had 53\% of floods). In Europe KG climate $\mathrm{D}$, spring floods were most common (May and June had 32\% of floods) and winter floods were more common than remaining months (December and January had $22 \%$ of floods). In North America, KG climate B (arid) major floods were most common in March and May and relatively common in January and June. In Europe, KG climate $\mathrm{E}$ (polar and alpine) major floods are predominantly in May through October, and particularly in May and August. There are very few gauges in our study from Europe KG climate B or North America KG climate E.

Monthly values of the Atlantic Multidecadal Oscillation (unsmoothed) and Pacific Decadal Oscillation were obtained from http://www.esrl.noaa.gov/psd/data/climateindices/list; water year values were calculated by averaging monthly values from October to the following September.

\subsection{Computation of flood thresholds}

Peak flows with return periods of 25, 50 and 100 years at each gauge were estimated by fitting a Generalized Extreme Value (GEV) distribution with L-moments (Hosking, 2013; R Development Core Team, 2014). The annual number of gauges where these thresholds were exceeded was then determined for each group of gauges. Peak flows were also computed with the Gumbel distribution. Overall patterns in the results were similar for the two distributions although there are some differences in which groups of gauges had significant trends (not shown). All exceedances for this study were based on the GEV distribution.

\subsection{Logistic regression}

Because of the large number of ties in the dataset (number of major floods in each year in each group of gauges) and the varying number of gauges in each year, use of the commonly used MannKendall test was not appropriate. Logistic regression with overdispersion correction (Frei and Schär, 2001; Frei, 2013) was therefore used for testing trends over time in major-flood occurrence (floods exceeding 25, 50 and 100 year flood magnitudes). For each group of streamflow gauges in the study, trends were tested for two periods, 1931-2010 and 1961-2010. Annual-maximum flows for all gauges 
Table 1

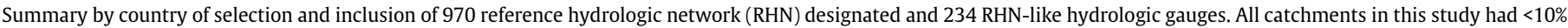

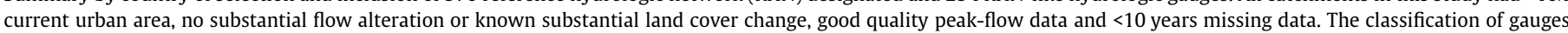

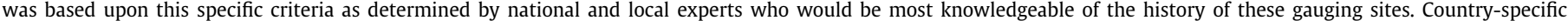
information and citations of reference hydrologic networks are below.

\begin{tabular}{|c|c|c|c|c|}
\hline Country & RHN & RHN-like & Comment & Reference \\
\hline Canada & 108 & & $\begin{array}{l}\text { Gauges from RHN matching study criteria were included. Nested stations removed except for } 2 \\
\text { just above nested criteria in the north where station density is low }\end{array}$ & Brimley et al. (1999) \\
\hline Denmark & & 23 & $\begin{array}{l}\text { Only gauges with no regulation were included by the Danish Centre for Environment and Energy. } \\
\text { Urbanisation at selected gauges ranged between zero and } 9 \% \text { with an average of } 3 \%\end{array}$ & \\
\hline Finland & & 36 & $\begin{array}{l}\text { Gauges were selected from a set used for a similar study and from this data set human influenced } \\
\text { (mainly regulation) stations were eliminated }\end{array}$ & Veijalainen et al. (2010) \\
\hline France & 190 & & $\begin{array}{l}\text { Data were inspected visually and tested for step-changes; local experts excluded gauges where } \\
\text { anomalies could be linked with particular events such as relocation of the station, rating curve } \\
\text { change, or construction affecting the river }\end{array}$ & Giuntoli et al. (2012) \\
\hline Germany & & 116 & $\begin{array}{l}\text { Gauges were either selected by the respective state agencies responsible for streamflow gauging } \\
\text { or based on detailed metadata on human influences on flow regulation, so that water regulation/ } \\
\text { abstractions/diversions were minimal and gauges perform well for floods }\end{array}$ & \\
\hline Iceland & & 3 & $\begin{array}{l}\text { Gauges were selected using the study criteria from the Icelandic Meteorological Office (IMO) } \\
\text { network, then screened by IMO experts so that land use change and water regulation/ } \\
\text { abstraction/diversion were minimal. Urban land for the selected catchments ranged between zero } \\
\text { and } 3 \%\end{array}$ & \\
\hline Ireland & 7 & & Gauges that met study criteria were selected from a designated RHN & Murphy et al. (2013) \\
\hline Norway & 78 & & Gauges that met study criteria were selected from a designated RHN & Fleig et al. (2013) \\
\hline Spain & & 14 & $\begin{array}{l}\text { Gauges are from an RHN-like network created for a study of detection and attribution of trends in } \\
\text { flood series in Spain }\end{array}$ & Mediero et al. (2014) \\
\hline Sweden & & 9 & Gauges were selected from a set used in a study with similar criteria that met study criteria & Wilson et al. (2010) \\
\hline Switzerland & & 33 & $\begin{array}{l}\text { Hydrological data and catchment metadata are well documented and centrally administered by } \\
\text { the Federal Office for the Environment (FOEN). Gauges used for the current study are the same as } \\
\text { those selected with the FOEN's expertise specifically for a study on flood trends }\end{array}$ & $\begin{array}{l}\text { Schmocker-Fackel and } \\
\text { Naef (2010) }\end{array}$ \\
\hline United Kingdom & 50 & & $\begin{array}{l}\text { Truly pristine catchments are rare in the UK, so modest levels of disturbance are tolerated in some } \\
\text { populated areas. Additional screening was required to ensure consistency with the criteria for the } \\
\text { current study. UK National River Flow Archive experts ensured that the urban extent was below } \\
10 \% \text { of catchment area, and that annual-maximum flow data were suitable. }\end{array}$ & $\begin{array}{l}\text { Bradford and Marsh } \\
\text { (2003) and Marsh (2010) }\end{array}$ \\
\hline United States & 537 & & $\begin{array}{l}\text { Gauges for the current study were required to be in the U.S. Geological Survey Hydro-Climatic } \\
\text { Data Network 2009. Further screening excluded catchments with }>10 \% \text { developed area }\end{array}$ & Lins (2012) \\
\hline
\end{tabular}

for 1961-2010 are in Supplementary Table 2 and annualmaximum flows for 1931-2010 are in Supplementary Table 3.

For logistic regression, let $X_{t}$ denote the random variable describing the number of major-flood occurrences at year $t$ in a given group, and $x_{t}$ the observed realization of this random variable. $X_{t}$ is assumed to follow a binomial distribution with parameters $\pi(t)$ and $n(t)$, whose probability mass function is:

$f(x ; \pi(t), n(t))=\operatorname{Pr}\left(X_{t}=x\right)=\left(\begin{array}{l}n(t) \\ x\end{array}\right)[\pi(t)]^{x}[1-\pi(t)]^{n(t)-x}$

In this notation, the value of $n(t)$ is known: it corresponds to the number of available gauges in the group at year $t . \pi(t)$ represents the local probability of major-flood occurrence, and is assumed to vary in time as follows:

$\pi(t)=\frac{\exp (\alpha+\beta t)}{1+\exp (\alpha+\beta t)}$

The function on the right hand side of the equation is the logistic function and ensures that parameter $\pi(t)$ lies in the range $[0,1]$. The unknown parameters $\alpha$ and $\beta$ are estimated by maximizing the likelihood function obtained with a sample of $M$ values $\left(x_{t}\right)_{t=t_{\text {star }}: t_{\text {end }}}\left(M=t_{\text {end }}-t_{\text {start }}+1\right)$. Assuming temporal independence between random variables $\left(X_{t}\right)_{t=t_{\text {start }}: t_{\text {end }}}$, this likelihood can be written as:

$L\left(x_{t_{\text {start }}}, \ldots, x_{t_{\text {end }}} ; \alpha, \beta\right)=\prod_{t=t_{\text {start }}}^{t_{\text {end }}} f\left(x_{t} ; \frac{\exp (\alpha+\beta t)}{1+\exp (\alpha+\beta t)}, n(t)\right)$

Let $\hat{\alpha}$ and $\hat{\beta}$ denote the parameters maximizing this likelihood. Instead of expressing the trend intensity as $\hat{\beta}$, it is customary to use the odds ratio, defined as $\frac{\hat{\pi}\left(t_{\text {end }}\right)}{1-\tilde{\pi}\left(t_{\text {end }}\right)} / \frac{\hat{\pi}\left(t_{\text {start }}\right)}{1-\hat{\pi}\left(t_{\text {start }}\right)}$. Here $\hat{\pi}(t)$ is the esti- mated probability of occurrence at time $t$, computed through Eq. (2) applied with $\hat{\alpha}$ and $\hat{\beta}$. When $\hat{\pi}(t)$ is small, the odds ratio is close to the probability ratio $\hat{\pi}\left(t_{\text {end }}\right) / \hat{\pi}\left(t_{\text {start }}\right)$. For example, an odds ratio of 2 indicates the probability of occurrence has doubled during the period and a ratio of 0.5 indicates it has halved.

Assessing trend significance is equivalent to assessing whether $\hat{\beta}$ is significantly different from zero. This can be achieved using a deviance test (also referred to as likelihood ratio test), which compares the maximized likelihood (3) with the maximized likelihood of a no-trend model, which can be written as:

$L_{0}\left(x_{t_{\text {start }}}, \ldots, x_{t_{\text {end }}} ; \gamma\right)=\prod_{t=t_{\text {start }}}^{t_{\text {end }}} f\left(x_{t} ; \gamma, n(t)\right)$

where $\gamma$ denotes the fixed probability of major-flood occurrence. The deviance statistic is then defined as:

$D=2\left[\log \left(L\left(x_{t_{\text {start }}}, \ldots, x_{t_{\text {end }}} ; \hat{\alpha}, \hat{\beta}\right)\right)-\log \left(L_{0}\left(x_{t_{\text {start }}}, \ldots, x_{t_{\text {end }}} ; \hat{\gamma}\right)\right)\right]$

Under the $\mathrm{H}_{0}$ hypothesis $\beta=0$, the deviance statistic $D$ asymptotically follows a chi-squared distribution with one degree of freedom, which allows performing the test.

The binomial distribution with parameters $\pi$ and $n$ has a mean equal to $n \pi$ and a variance equal to $n \pi(1-\pi)$; in other words, the variance is equal to $(1-\pi)$ times the expectation. It is common to observe in practice, however, that the sample variance is much higher than $(1-\hat{\pi})$ times the sample mean (where $\hat{\pi}$ is an estimate of $\pi$ ): the variance of the data is larger than it should be under a binomial assumption. This phenomenon is therefore referred to as "overdispersion". Overdispersion has been studied by statisticians in the context of logistic regression and generalized linear models (McCullagh and Nelder, 1989; Mediero et al., 2015). It 

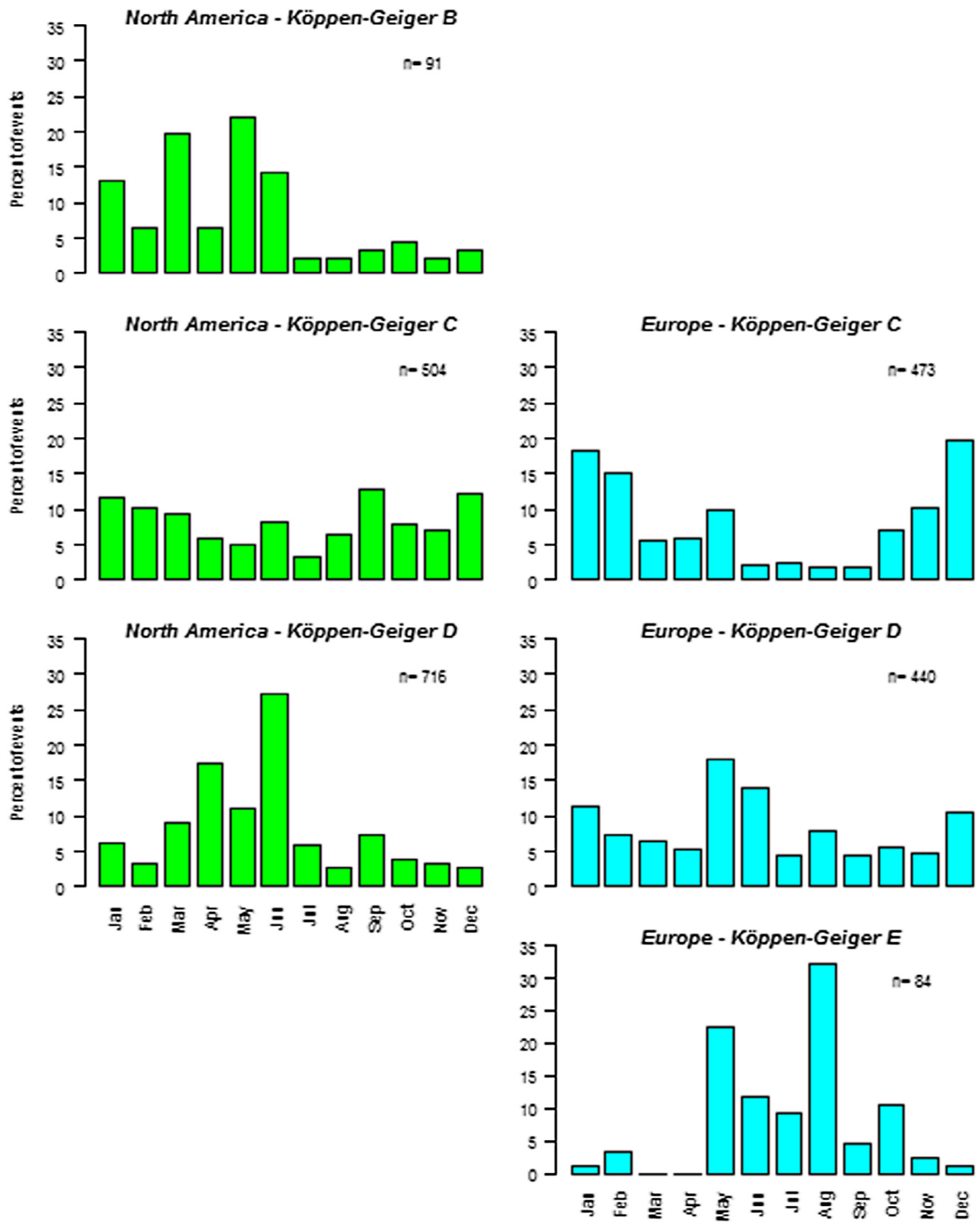

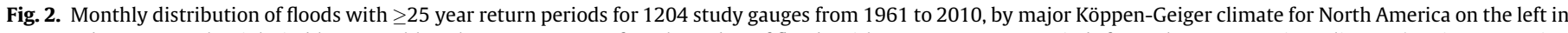

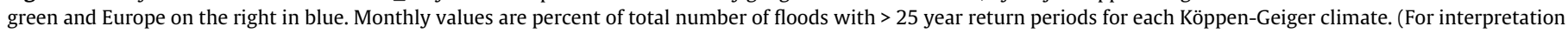
of the references to colour in this figure legend, the reader is referred to the web version of this article.)

can be quantified by means of an overdispersion coefficient, estimated as:

$\hat{\sigma}^{2}=\frac{1}{M-p} \sum_{t=t_{\text {start }}}^{t_{\text {end }}} \frac{\left(x_{t}-n(t) \hat{\pi}(t)\right)^{2}}{n(t) \hat{\pi}(t)(1-\hat{\pi}(t))}$

where $M$ is the sample size and $p$ is the number of estimated parameters in the logistic regression. This coefficient can then be used to account for overdispersion in hypothesis testing, by replacing the deviance statistic $D$ in Eq. (5) by $D / \hat{\sigma}^{2}$ (McCullagh and Nelder, 1989).

After computing trends, major-flood occurrence for each group was related to two ocean/atmosphere indices, the AMO and PDO, to analyse multidecadal variability in major-flood occurrence. Logistic regression was used for this purpose, by regressing annual major-flood occurrence for each group of gauges against annual values of the AMO and PDO (instead of time). 


\section{Results}

\subsection{Trends in major-flood occurrence}

The overall occurrence of major floods in Europe from 1961 to 2010 increased, but not significantly, based on floods at 559 gauges (Fig. 3). The overall occurrence of major floods at 645 gauges in North America changed very little over this period. For the period 1931-2010, the overall occurrence of major floods in Europe (128 gauges) changed very little whilst floods increased overall in North America (194 gauges) but not significantly except for 25 year floods (Fig. 4).

Trends over time were computed for groups of gauges defined by catchment size, location, climate, flood threshold and period of record (Figs. 5 and 6). Gauges were grouped by catchment size and Köppen-Geiger climate (Peel et al., 2007) to explore whether trends were related to different overall flood generating processes. Dividing gauges into smaller, more homogeneous groups, is beyond the scope of the current study and would result in many groups with too few catchments to obtain robust results. Also, floods even at individual gauges can have multiple flood generating processes (Waylen and Woo, 1982).

There were a total of 246 tests for trends over time in majorflood occurrence for the two periods tested, one test for each group of gauges with $>10$ catchments (Figs. 5 and 6). There were 12 significant trends over time (5\% significance level) for these 246 tests; this is approximately the number of significant trends expected due to chance alone, even without accounting for field significance.

Despite records overlapping by up to 50 years, different patterns of change were detected between the two periods
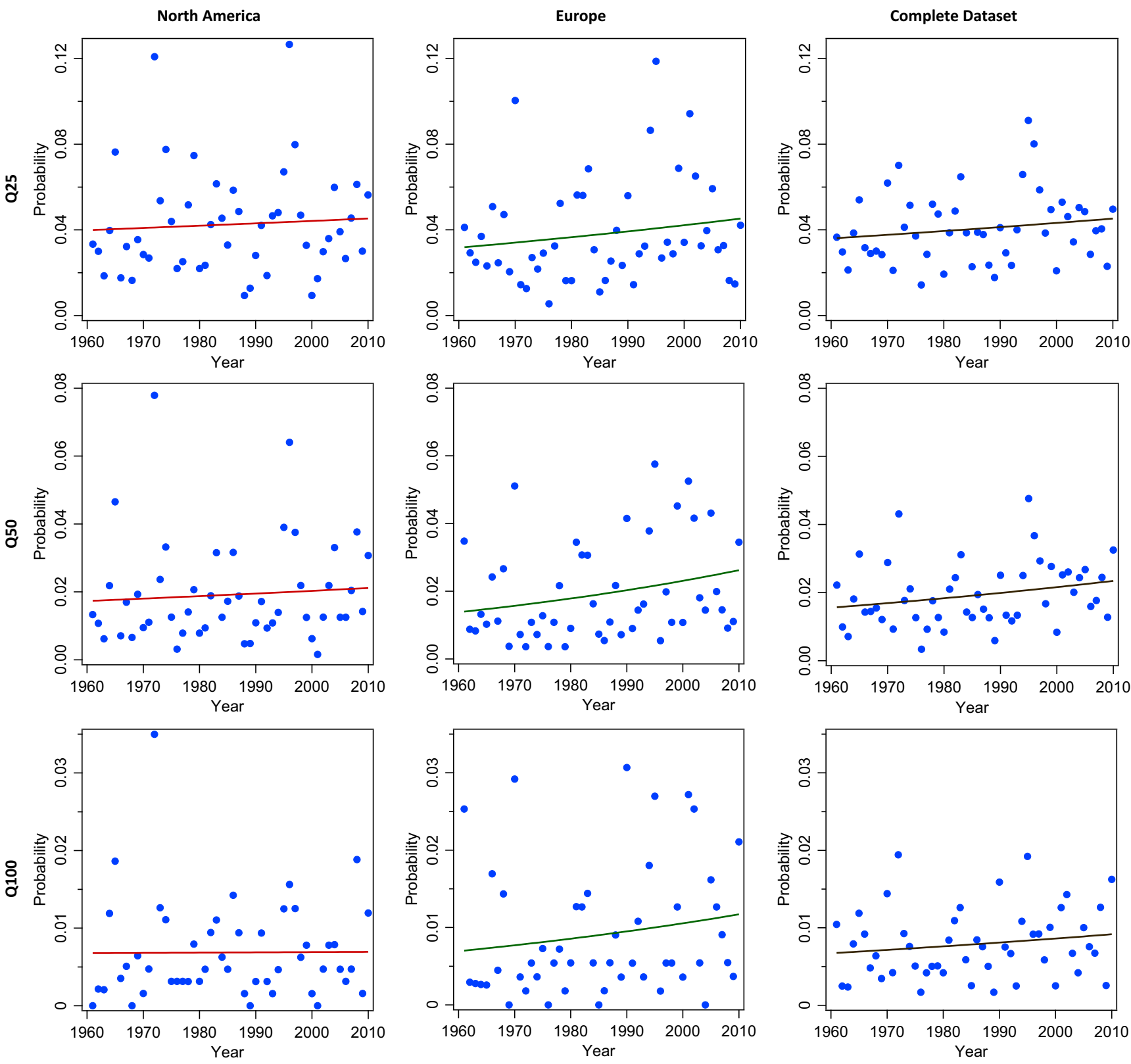

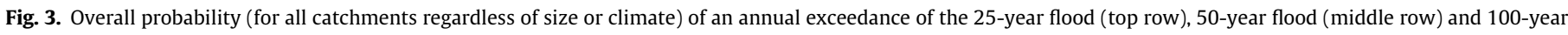

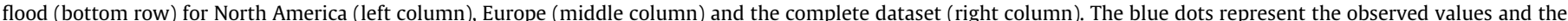

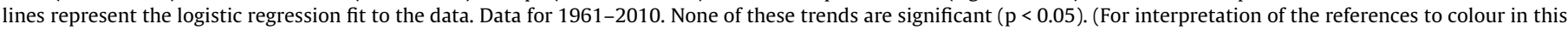
figure legend, the reader is referred to the web version of this article.) 

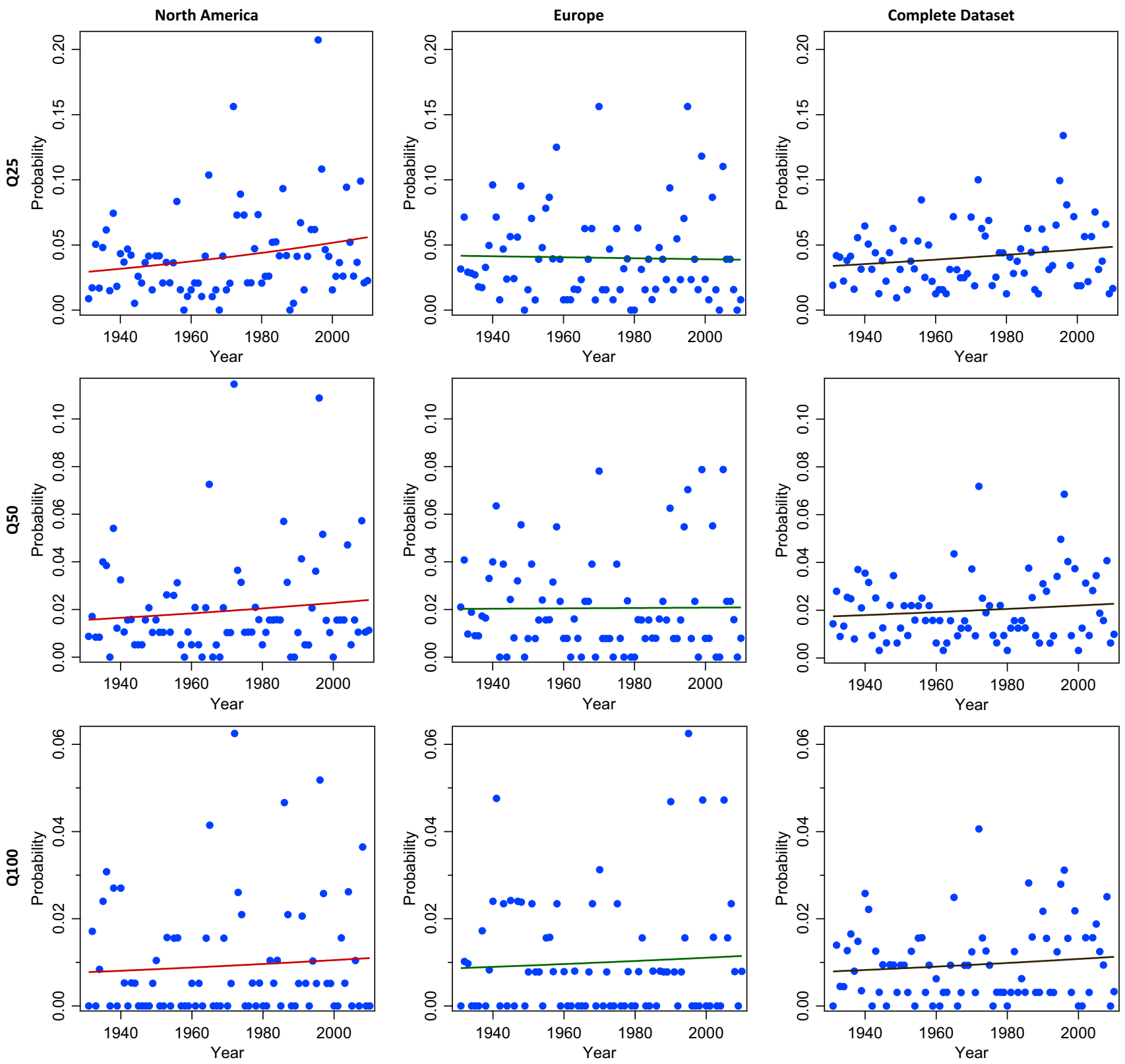

Fig. 4. Overall probability of annual exceedance, as for Fig. 3 but for period from 1931 to 2010 . Only the trend for the 25-year flood for North America is significant.

considered. For 1961-2010, there were significant increases in major-flood occurrence for 50 year floods at medium (100$1000 \mathrm{~km}^{2}$ ) catchments in Europe, particularly those in KG climate C (Fig. 5). For the 1931-2010 period, there were significant increases for 25 year floods at large $\left(>1000 \mathrm{~km}^{2}\right)$ catchments in North America, particularly in KG climate D (Fig. 6). For this longer time period, there were also significant decreases for 50 year floods at small catchments in the complete dataset and significant increases for 100 year floods at medium catchments.

The limited number and distribution of gauges for 1931-2010 may be partly responsible for differences between periods; however, Europe had relatively few major floods in the 1960s and 1970s (Fig. 4) which helps drive the increasing trends from 1961 to 2010. North American trends from 1931 to 2010 were influenced by the relatively few major floods in the 1930s and 1940s (Fig. 4). Overall, it is difficult to generalize the results grouped by climate and catchment area since there were few significant trends in either period.
Using only the 322 gauges in Europe and North America with 1931-2010 data, 1961-2010 major-flood occurrence trends were recomputed (not shown); the overall patterns of change were similar to the 1961-2010 trends using all 1204 gauges, although there were no significant trends. This indicates that the differences in flood occurrence trends between the two periods were due to climatic differences rather than different geographic distributions of gauges.

\subsection{Relation between major-flood occurrence and ocean/atmosphere indices}

There were no significant relationships, for any group of catchments, between flood occurrence and the Pacific Decadal Oscillation (PDO) for the 1961-2010 period (Fig. 7). The Atlantic Multidecadal Oscillation (AMO) had a significant negative relationship with 25 and 50 year flood occurrence for large catchments in North America, and a significant positive relationship with 25, 50 

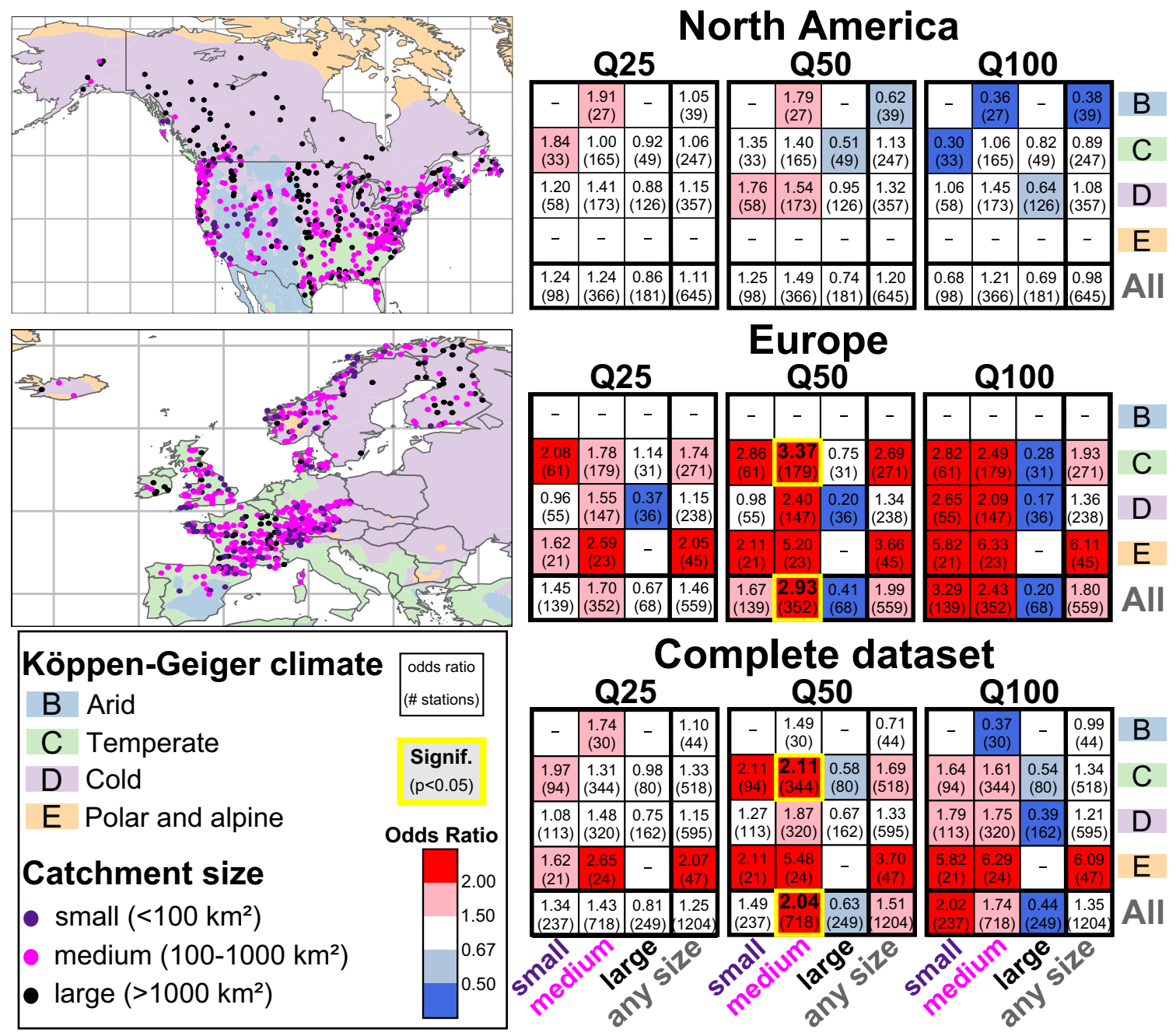

\section{Europe}

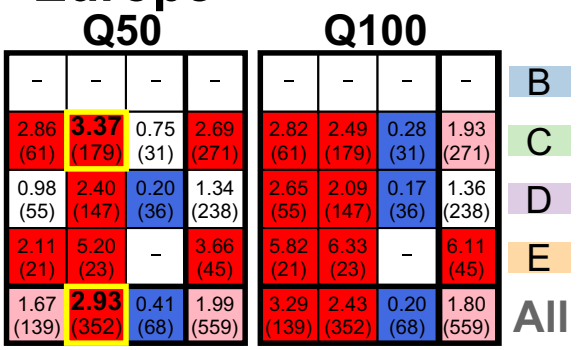

\section{Complete dataset}

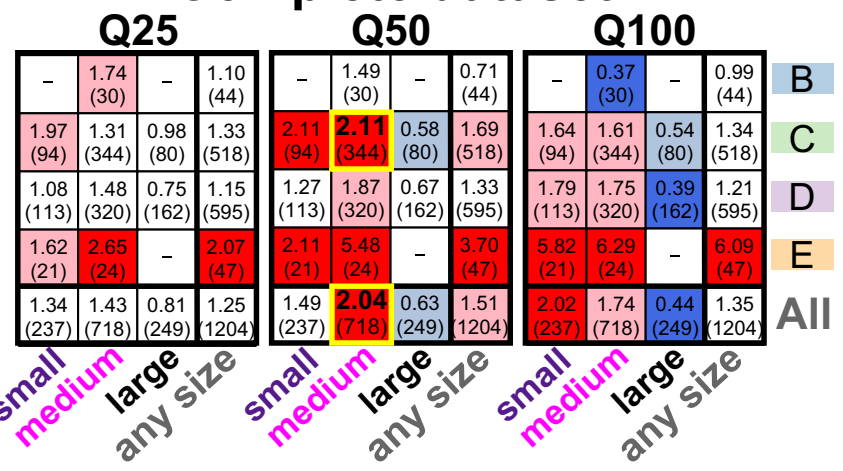

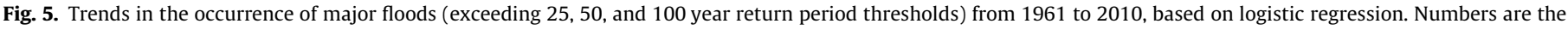

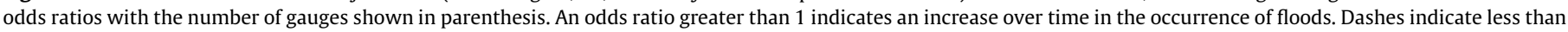

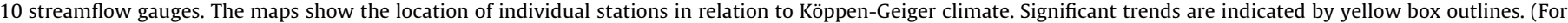
interpretation of the references to colour in this figure legend, the reader is referred to the web version of this article.)

and 100 year flood occurrence for medium catchments in Europe (Fig. 8) and a total of 23 significant relationships for the 19612010 period.

The relationships for 1931-2010 between major flood occurrence and the AMO were similar to results for 1961-2010 (not shown) although fewer groups of catchments had significant relationships (16 total). Figs. 9 and 10 illustrate the negative relationship between the AMO and flood occurrence for North America and the positive relationship in Europe. There were also periods that deviate from the overall relationships (e.g. relatively high occurrence of floods in North America in the 1940s and relatively low occurrence of floods in Europe in the 2000s). Fig. 9 shows scatterplots with logistic regression lines of annual probability of major floods vs. annual AMO, for 25 year flood exceedances at North American large $\left(>1000 \mathrm{~km}^{2}\right)$ catchments and 50 year flood exceedances at European medium (100-1000 $\left.\mathrm{km}^{2}\right)$ catchments. Fig. 10 shows plots of the smoothed time series of AMO, and 25 year flood occurrence for North American large catchments and 50 year flood occurrence for European medium catchments, for the period 19312010.

\section{Discussion}

\subsection{Comparison of results to previous studies}

There was no compelling evidence for consistent changes over time in major-flood occurrence during the 80 years through 2010 , using a very large dataset ( $>1200$ gauges) of diverse but minimally altered catchments in North America and Europe. These results differ from the most comparable previous study (Milly et al., 2002), which found significant increases in the occurrence of 100 year floods during the 20th century for 16 very large catchments in Northern Hemisphere extratropical areas; flood trends at these catchments may be impacted by human alterations. The two studies are not necessarily in conflict as the study areas do not completely overlap, a much greater number and diversity of catchments (but all minimally altered) are assessed here, and also the current study captures the most recent shift in the AMO. Studies where the time frame spans only two phases of the AMO could mistakenly confuse flood trends with lowfrequency variability. 

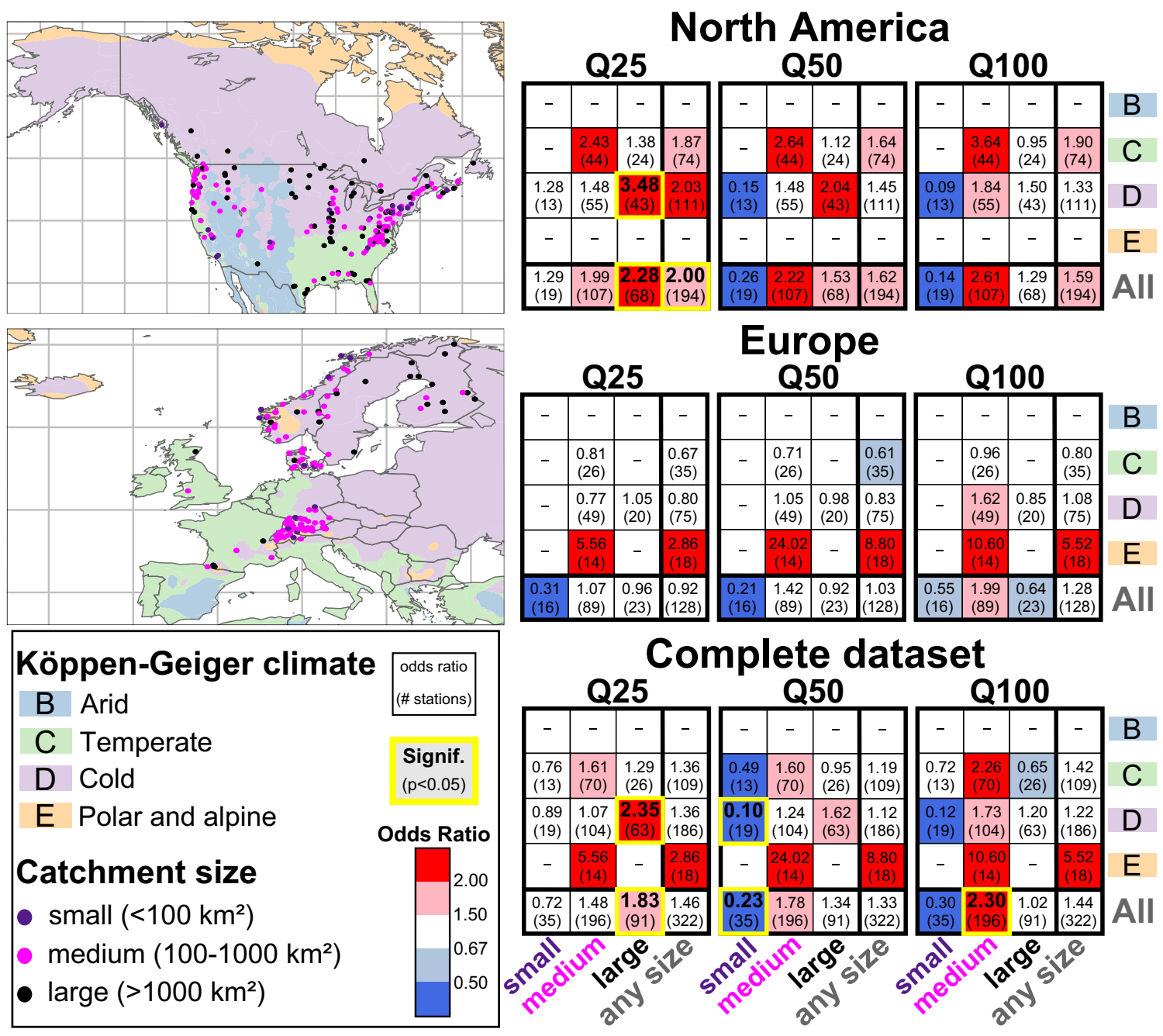

Fig. 6. Trends in the occurrence of major floods from 1931 to 2010, based on logistic regression. See Fig. 5 for explanation.

Although there were no more trends than expected due to chance alone in the present study, catchment size, location, climate, period of record and flood threshold influence the significance or even the direction of flood-occurrence trends. Therefore, it should not be assumed that the occurrence of major floods is increasing across large domains for a diversity of catchment types. For North America and Europe, the results provide a firmer foundation for the IPCC finding that compelling evidence for increased flooding at a global scale is lacking (Hartmann et al., 2013).

Focusing on the few groups of catchments where significant increases over time in major-flood occurrence were found, our results are consistent with published studies indicating increases in flood flows or heavy or extreme precipitation. Previous studies showed annual-maximum flow increases in central and northern Europe from the 1960s to the 2000s (Hall et al., 2014; Stahl et al., 2012) and others demonstrated the importance of multidecadal variability influencing trends over this period (Hannaford et al., 2013). The occurrence of 50 year floods significantly increased for medium sized $\left(100-1000 \mathrm{~km}^{2}\right)$ catchments in Europe from 1961-2010; numerous studies at the European scale-consistent with the results of the current study-have identified increases in indicators of heavy rainfall for similar time periods (Klein Tank and Können, 2003; Moberg et al., 2006; Dyrrdal et al., 2012; Madsen et al., 2014), although these studies all point towards significant regional variations. There have been few studies looking at changes over time in precipitation extremes; overall increases in the occurrence of precipitation extremes ( 1 and 5 day precipitation for 5, 10 and 20 year return periods) in northern Europe in autumn, winter and spring for 1951-2010 have been shown (Van den Besselaar et al., 2013).

The occurrence of 25 year floods significantly increased for large catchments in North America KG climate D from 1931 to 2010. Most of these catchments are in the northern part of the United States and the southern edge of Canada. Many are in the northeastern quadrant of the United States; Peterson et al. (2013) found many increases over time in annual maximum flows in this area at long-term gauges (>85 years of record). Trends in heavy and extreme precipitation are consistent with increases in the occurrence of major floods for large $\left(>1000 \mathrm{~km}^{2}\right)$ catchments (Kunkel, 2003). North American trends in extreme precipitation (1, 5 and 30 day precipitation for 1,5 and 20 year return periods) show a sizable increase in the frequency of extremes in the United States since the 1920s and 1930s; however, the frequency of extremes in the 1980s and 1990s were similar to those of the late $1800 \mathrm{~s}$ and early 1900s. There was no discernible trend in the frequency of extreme events in Canada.

Whilst the seasonality of major floods in Köppen-Geiger regions (as seen in Fig. 2) is an overall indicator of the flood-generating mechanisms in each major KG region, there are multiple flood generating mechanisms in each region. It is beyond the scope of the 

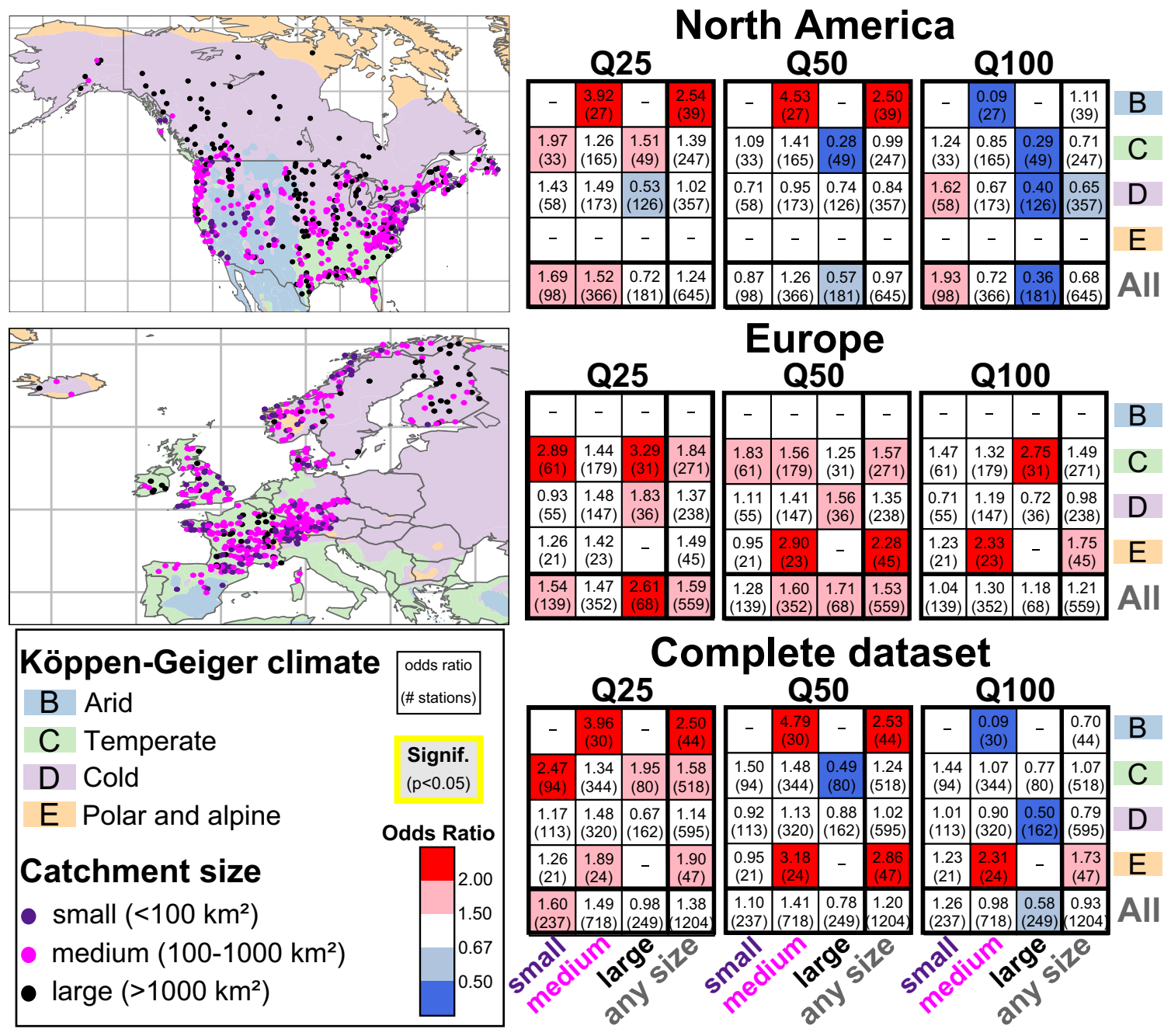

Europe
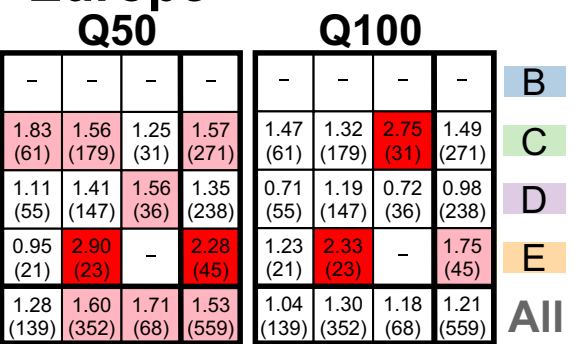

Köppen-Geiger climate

B Arid

Complete dataset

Q25

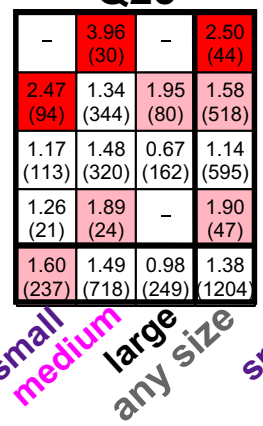

Q50

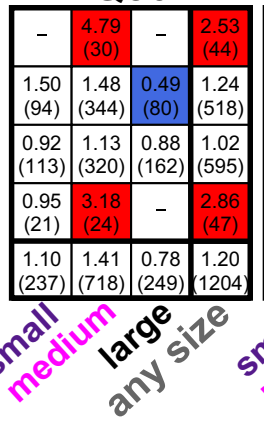

Q100

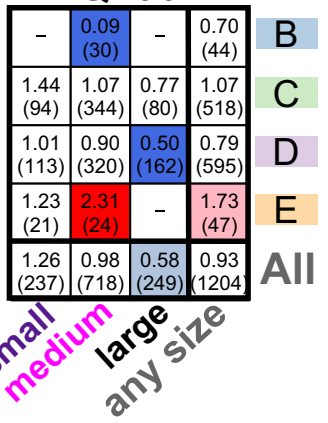

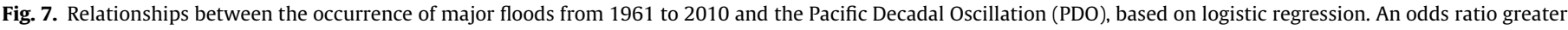
than 1 indicates a positive relationship. See Fig. 5 for other explanation.

current study to resolve trends in the occurrence of major floods for individual generating mechanisms across North America and Europe.

\subsection{Relation between major-flood occurrence and ocean/atmosphere indices}

This study shows that large-scale multidecadal ocean/atmosphere variability, as represented by the Atlantic Multidecadal Oscillation index, is related to major-flood generation. There were more than three times as many significant relationships between major-flood occurrence and the AMO for 1961-2010 and 19312010 than significant trends over time for these periods. Further research is needed to determine the processes by which the AMO affects major floods in large North American catchments and medium European catchments, such as changes to synoptic scale and mesoscale patterns that influence heavy rainfall generating processes. No previously published research is known on the influence of the AMO on major floods; however, work has been published on relationships with mean flows, precipitation and drought.

The influence of the AMO on major floods is consistent with the influence of the AMO on general dryness in North America and wetness in Europe. A number of studies have analysed the influence of the AMO on the hydrology of North America and Europe.
A negative relationship between North Atlantic sea surface temperatures and annual runoff was found in most of North America and a positive relationship in most of Europe (McCabe and Wolock, 2008). A relationship between the AMO and the Palmer Drought Severity Index (PDSI) was found for many parts of the world with a negative relationship over much of North America and in southern Europe, indicating dry conditions in a positive AMO (McCabe and Palecki, 2006). The US sees below normal rainfall during AMO positive phases, (Enfield et al., 2001) whilst in northern Europe there are wet conditions in a positive AMO (McCabe and Palecki, 2006). Above or below normal rainfall may impact antecedent conditions important to major floods. Further research, however, is needed to determine whether antecedent conditions have played a significant role in increasing or reducing the occurrence of major floods. It is possible, for example, that wet periods reflect rain from individual heavy events rather than indicating wet antecedent conditions.

In North America, some studies have found relationships between the AMO and heavy precipitation for selected seasons; relationships between both heavy rainfall and mean rainfall and the AMO for August, September and October showed mixed positive and negative relationships across the United States (Curtis, 2008). Less frequent summer storms and precipitation were found in most of North America in positive AMO periods due to a chain of 

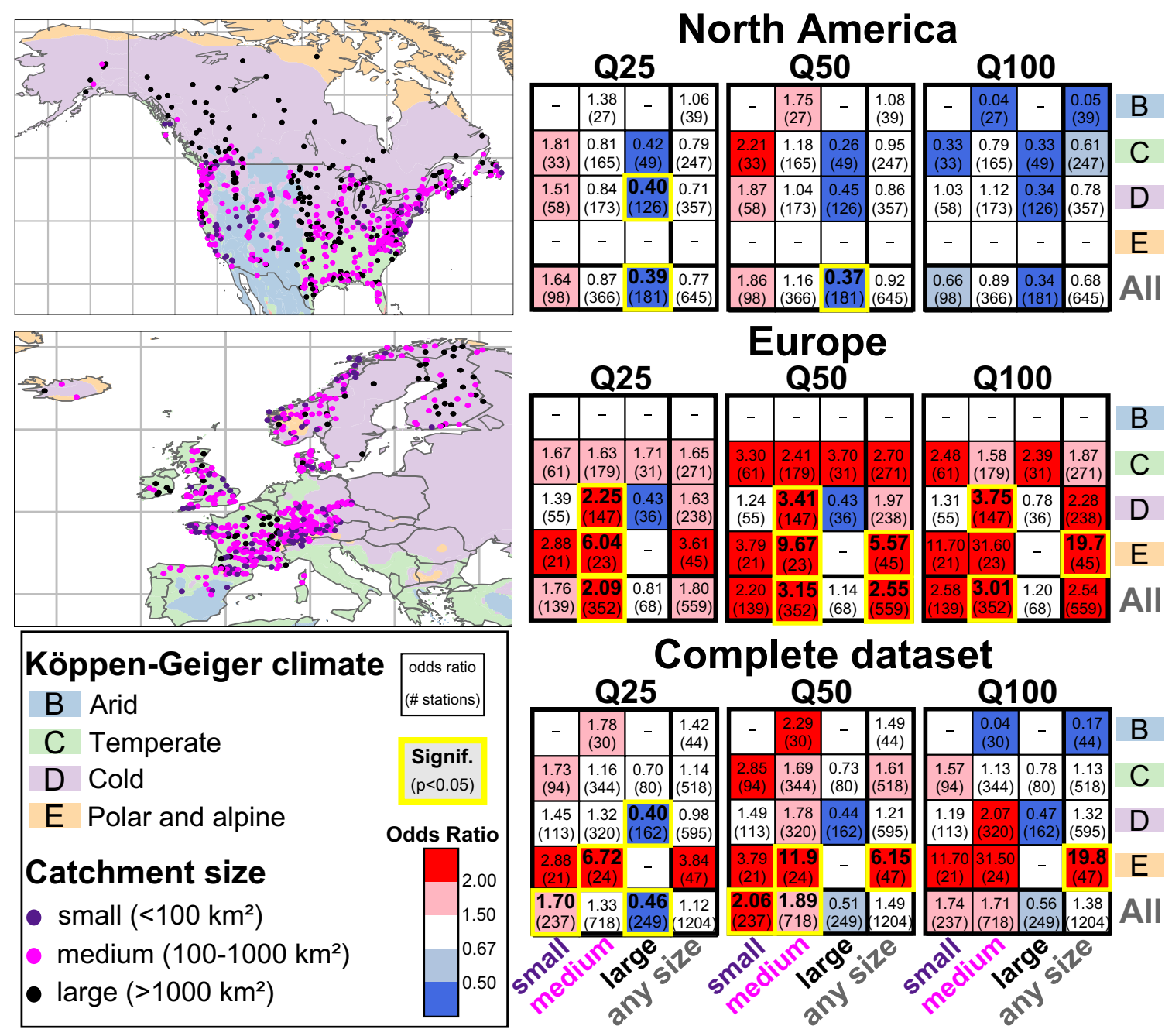

\section{Europe}
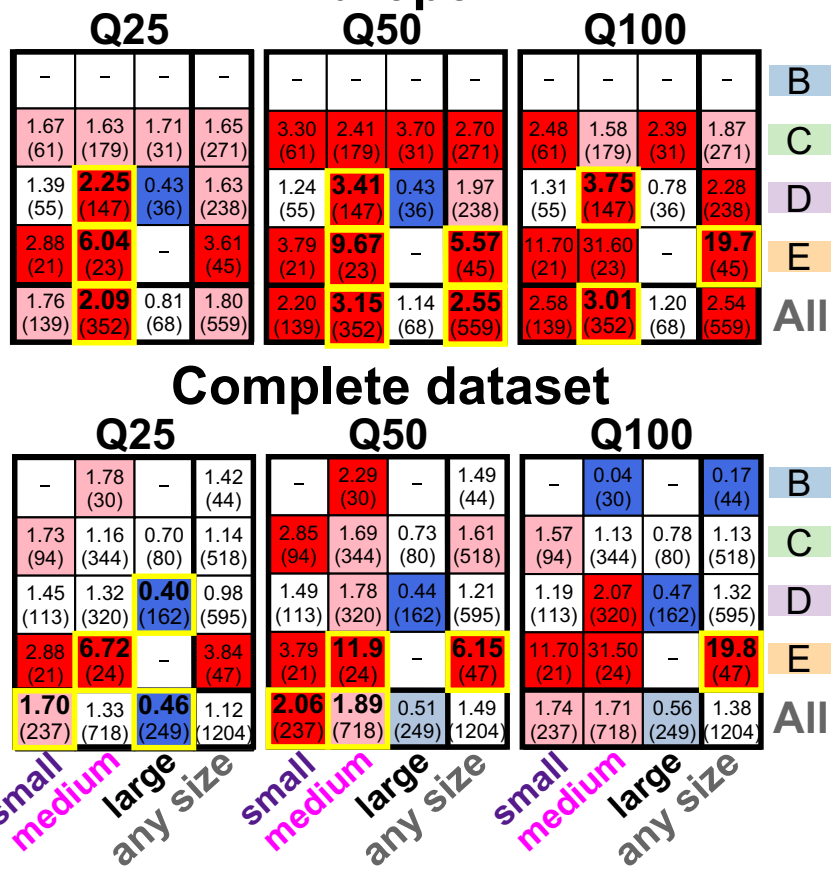

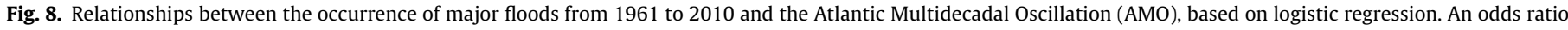
greater than 1 indicates a positive relationship. See Fig. 5 for other explanation.

events following different circulation anomalies during positive and negative phases (Hu et al., 2011).

In Europe, the influence of the AMO warm phase on storm tracks and rainfall is well established (Knight et al., 2006; Sutton and Dong, 2012; Dong et al., 2013), although the strongest relationships have been found in summer and autumn; less compelling results have been found for the winter which is the primary flood season in much of western Europe. Furthermore, these studies have tended to focus on seasonal precipitation averages rather than extremes, which have been studied only rarely. Positive AMO has been linked to heavy precipitation in Europe across all seasons, using a high-resolution gridded dataset; the link between AMO and heavy precipitation was attributed to the role of warm Atlantic sea-surface temperatures as a provider of available moisture (Casanueva et al., 2014).

For an accurate portrayal of expected future changes in major floods, it is important that projections consider the influence of multidecadal oscillations, such as the AMO, on major-flood occurrence. Not all multidecadal oscillations will affect the occurrence of major floods, however. In the present study, there were no significant relationships, for any group of catchments, between major flood occurrence and the PDO for the 1961-2010 period (Fig. 7). These results are different than those of many studies which have shown local impacts of the PDO on streamflow in North America.
Jain and Lall $(2000 ; 2001)$ reported that flood potential varied with PDO phase in Utah and Washington. Burn et al. (2004) found annual-maximum flows were earlier and lower during the warm phase of the PDO than in the cool phase in the Liard Basin in Canada. Gurrapu et al. (2016), using a collection of reference and non-reference hydrologic stations, showed that in western Canada higher magnitude floods may be occurring during the cool phase of the PDO. Whitfield et al. (2010) provided a review of the effect of the PDO in western Canada; they reported that it is a useful post hoc explanatory concept when considering climate and streamflow.

The PDO results presented here use different variables than previous studies; major floods were examined rather than annual maxima. Another difference is that the current study used long data records for common periods (including different and more recent time periods than in other studies) and stations were restricted to minimally altered catchments from a reference hydrologic network or equivalent sites; this has seldom been the case in other studies. Also, the physical scale of the present study is more extensive than for many other studies, where the focus has often been on a small geographic area. If we had focused on a specific area of the west coast of North America, a different result with regard to the PDO may have occurred. Burn and Whitfield (2017) considered century long records from a small number of references 
(a) North America - Large Catchments - Q25

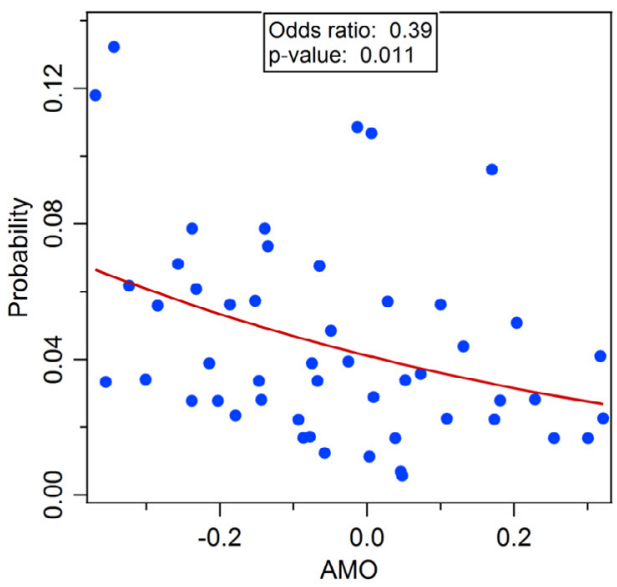

(b) Europe - Medium Catchments - Q50

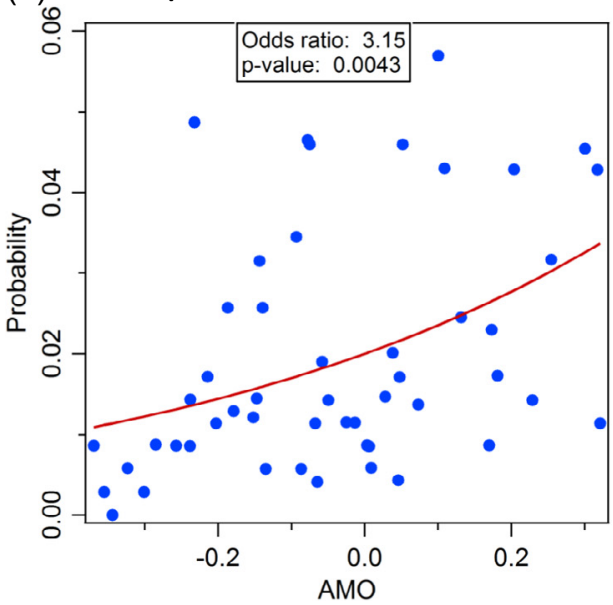

Fig. 9. (a) Probability of annual exceedances of the 25-year flood at large catchments in North America plotted against annual values of the Atlantic Multidecadal Oscillation (AMO) for 1961-2010. (b) Probability of annual exceedances of the 50-year flood at medium catchments in Europe plotted against annual values of the AMO for 1961-2010. The blue dots represent the observed values and the lines represent the logistic regression fit to the data. (For interpretation of the references to colour in this figure legend, the reader is referred to the web version of this article.)

sites in Canada and the United States and suggested the differences between their PDO results, and those of others, can be explained by the longer time period examined and the exclusive use of reference hydrologic network sites, where the effects of non-climatic factors have been minimized.

\subsection{Data and methodological caveats}

Merz et al. (2012) argue that properly detecting changes in flooding over time requires a stricter approach than many previous studies have used. The approach needs to start by selecting stations that are suitable for the type of question that is being asked. Here, to meet the criteria, reference hydrologic network stations were selected by expert review to isolate climate system drivers from other drivers. The stations selected have relatively undisturbed flow regimes (near-natural and largely unregulated) and are gauged by stations that produce good quality hydrologic data (Whitfield et al., 2012; Burn et al., 2012). We see this selection step as an essential part of any study aimed at detecting climate-related variability or trends. However, this selection is challenging, especially at the multi-national scale, because each country manages (a)

North America - Large Catchments - Q25

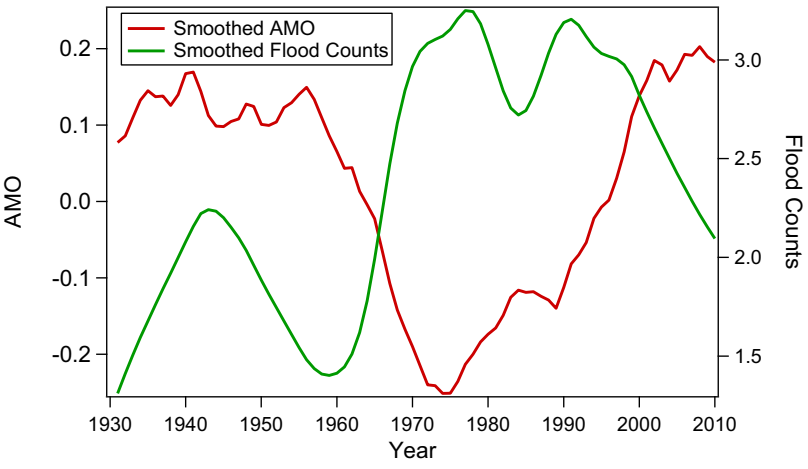

(b)

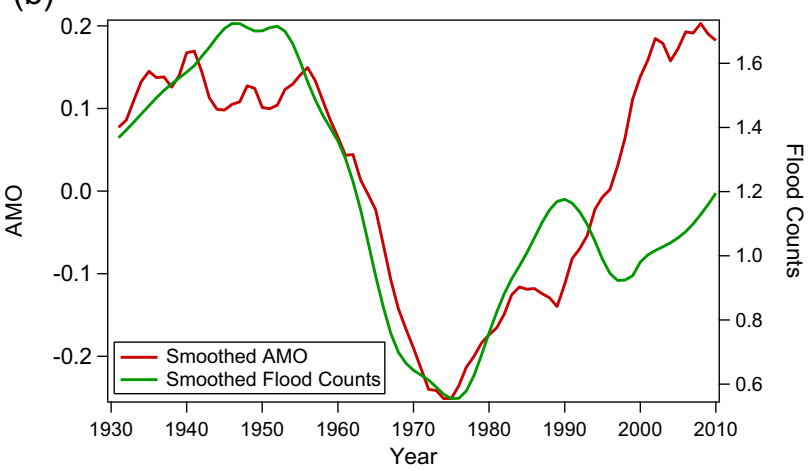

Fig. 10. (a) Time series plots from 1931 to 2010 of smoothed Atlantic Multidecadal Oscillation (AMO) and 25 year flood occurrence for large catchments in North America. (b) Time series plots of smoothed AMO and 50 year flood occurrence for medium catchments in Europe. Smoothing was done using the Lowess smoothing technique with a window corresponding to $30 \%$ of the data.

river flow data in a specific way (in terms of accessibility, available metadata information, measurement practices, etc.). This calls for a coordinated effort by the hydrological community to make national RHN data available. The annual maxima we used in this paper are available in supplemental tables. Many daily series (although not all, due to access restrictions) are available through the Global Runoff Data Centre (GRDC, www.bafg.de/GRDC/EN/ Home/homepage_node.html) or from national websites.

In addition to using appropriate data, meaningful trend detection requires using appropriate statistical methods. In this work, the logistic regression approach was favored over more commonly used methods such as the Mann-Kendall test because it is more appropriate for the count data we used. In particular, the large number of ties in the dataset and the varying total number of gauges in each year can be handled straightforwardly. Logistic regression makes the assumption that the count data are realizations from a binomial distribution. The binomial distribution is by definition the number of successes in independent Bernoulli trials, with each trial having the same success probability $\pi$. If "success" is defined as a major flood occurrence, this closely corresponds to the data analysed in the paper. However, two of the binomial assumptions are likely not met by our data:

1. The trials are not independent: this is due to spatial dependence between nearby sites.

2. The success probability varies from site to site: whilst exceedance thresholds are defined as p-quantiles with the same $p$ for all sites, those quantiles are only estimates and are hence affected by estimation errors. Consequently, the actual success probability $\pi$ may vary from site to site. 
The purpose of the overdispersion correction described in Section 2.3 is precisely to account for such misspecifications. We performed Monte Carlo experiments (not shown) and confirmed that the overdispersion correction is necessary and sufficient to account for the two issues above: in its absence, the logistic regression test is highly biased, in the sense that it detects many spurious trends; however the test becomes virtually unbiased with the correction, even with datasets showing large spatial dependence and success probabilities strongly varying from site to site.

Finally, the logistic regression test also assumes that data are independent in time. Logistic regression was not robust, however, to autocorrelation when tested by Monte Carlo experiments (not shown). Autocorrelation was present in North America, but not Europe, when tested by bootstrap permutation (not shown); it was significant $(\mathrm{p}<0.05$ ) in North America for 25 year exceedances for both periods and for 50 year exceedances for the 1961-2010 period. Autocorrelation was not significant for 50 year exceedances for the 1931-2010 period or for 100 year exceedances for either period. Autocorrelation results in rejection rates higher than the nominal level. Since the number of significant trends in this study was not more than the number expected due to chance alone autocorrelation did not play a significant role in the interpretation of results.

\section{Conclusions}

Reference hydrologic networks isolate catchments where climate has been the principal driver of streamflow change by minimizing other drivers, such as regulation, diversions and urbanisation. The relationship between floods and climate change is more difficult to discern where catchments have been altered, making attribution to any single driver uncertain.

Trends over time in the occurrence of major floods (exceeding 25, 50, and 100 year return periods) in North America and Europe were evaluated for 1961-2010 and 1931-2010. All gauges drain catchments that are considered by local and national experts to be minimally affected by catchment alterations. Trend testing of major floods required the grouping of gauges. The 1204 gauges that met study criteria for 1961-2010 and the 322 gauges for 1931-2010 were grouped by continent, Köppen-Geiger climate and catchment size. The number of significant trends for 246 groups of gauges was approximately the same as would be expected by chance alone.

There were more than three times as many groups of gauges with significant relationships between the number of annual major floods and annual values of the Atlantic Multidecadal Oscillation than expected due to chance. Catchment size was important to the results; there were significant negative relations between floods and the AMO at large $\left(>1000 \mathrm{~km}^{2}\right)$ North American catchments and significant positive relations at medium (100$1000 \mathrm{~km}^{2}$ ) European catchments. The opposite relations between European and North American major flood occurrence and the AMO are consistent with previous work on general wetness and dryness related to the AMO. There were no significant relationships, for any group of catchments, between major flood occurrence and the Pacific Decadal Oscillation.

The results of this study, for North America and Europe, provide a firmer foundation and support the conclusion of the IPCC (Hartmann et al., 2013) that compelling evidence for increased flooding at a global scale is lacking. Generalizations about climate-driven changes in floods across large domains or diverse catchment types that are based upon small samples of catchments or short periods of record are ungrounded. Networks of streamflow data from minimally altered catchments will provide an essential foundation for future efforts to understand the complex temporal and spatial dynamics of major floods.

\section{Acknowledgments}

The authors would like to express their appreciation to all the agencies from the countries that made the streamflow data available for this study: Water Survey of Canada; Danish Centre for Environment and Energy; Finnish Environment Institute; the HYDRO database from the French Ministry of the Environment, Energy and the Sea; the environment agencies of the Federal States of Germany (Bayrisches Landesamt für Umwelt; Landesanstalt für Umwelt, Messungen und Naturschutz, Baden-Württemberg; Landesamt für Umwelt, Wasserwirtschaft ind Gewerbeaufsicht, Rheinland-Pfalz; Hessisches Landesamt für Umwelt und Geologie; Sächsisches Landesamt für Umwelt, Landwirtschaft und Geologie); Icelandic Meteorological Office; Environmental Protection Agency and Office of Public Works in Ireland; Norwegian Water Resources and Energy Directorate; Centre for Hydrographic Studies of CEDEX of Spain; Swedish Meteorological and Hydrological Institute; Swiss Federal Office for the Environment; United Kingdom National River Flow Archive; and the United States Geological Survey. We thank Petra Schmocker-Fackel for providing a list of appropriate gauges for Switzerland and Philippe Crochet for providing a list for Iceland. The authors appreciate the suggestions and comments of Gregory McCabe Alberto Viglione and an anonymous reviewer.

\section{Appendix A. Supplementary data}

Supplementary data associated with this article can be found, in the online version, at http://dx.doi.org/10.1016/j.jhydrol.2017.07. 027.

\section{References}

Archfield, S.A., Hirsch, R.M., Viglione, A., Blöschl, G., 2016. Fragmented patterns of flood change across the United States. Geophys. Res. Lett. 43. http://dx.doi.org/ 10.1002/2016GL070590.

Arnell, N.W., Gosling, S.N., 2016. The impacts of climate change on river flood risk at the global scale. Clim. Change 134, 387-401.

Bradford, R.B., Marsh, T.J., 2003. Defining a network of benchmark catchments for the UK. Water Maritime Eng. 156, 109-116.

Brimley, B. et al., 1999. Establishment of the reference hydrometric basin network (RHBN) for Canada. Environment Canada, Ottawa, p. 41.

Burn, D.H., Cunderlik, J.M., Pietroniro, A., 2004. Hydrological trends and variability in the Liard River basin. Hydrol. Sci. J. 49, 53-67.

Burn, D.H., Hag Elnur, M.A., 2002. Detection of hydrologic trends and variability. J. Hydrol. 255, 107-122.

Burn, D.H. et al., 2012. Hydrologic reference networks II. Using reference hydrologic networks to assess climate driven changes in streamflow. Hydrol. Sci. J. 57 1580-1593.

Burn, D.H., Whitfield, P.H., 2016. Changes in floods and flood regimes in Canada. Can. Water Resour. J. 41, 139-150.

Burn, D.H., Whitfield, P.H., 2017. Changes in cold region flood regimes inferred from long record reference gauging stations. Water Resour. Res. 53. http://dx.doi.org/ 10.1002/2016WR020108.

Casanueva, A., Rodriguez-Puebla, C., Frias, M.D., González-Reviriego, N., 2014. Variability of extreme precipitation over Europe and its relationships with teleconnection patterns. Hydrol. Earth Syst. Sci. 18, 709-725.

Curtis, S., 2008. The Atlantic Multidecadal Oscillation and extreme daily precipitation over the US and Mexico during the hurricane season. Clim. Dyn. 30, 343-351.

Dong, B.W., Sutton, R.T., Woollings, R.T., Hodges, K., 2013. Variability of the North Atlantic summer storm track: mechanisms and impacts on European climate. Environ. Res. Lett. 8, 034037.

Dyrrdal, A.V., Isaksen, K., Hygen, H.O., Meyer, N.K., 2012. Changes in meteorological variables that can trigger natural hazards in Norway. Clim. Res. 55, 153-165.

Enfield, D.B., Mestas-Nunez, A.M., Trimble, P.J., 2001. The Atlantic Multidecadal Oscillation and it's relation to rainfall and river flows in the continental U.S. Geophys. Res. Lett. 28, 2077-2080.

Fleig, A.K. et al., 2013. Norwegian hydrological reference dataset for climate change studies. NVE Report, 2-2013.

Frei, C., 2013. Trend R-package, version 1.5.1. 
Frei, C., Schär, C., 2001. Detection probability of trends in rare events: theory and application to heavy precipitation in the Alpine region. J. Clim. 14, 1568-1584.

Giuntoli, I., Renard, B., Lang, M., 2012. Floods in France. In: Kundzewicz, Z.W. (Ed.), Changes in Flood Risk in Europe, pp. 200-211.

Gurrapu, S., St. Jacques, J.-M., Sauchyn, D.J., Hodder, K.R., 2016. The influence of the Pacific Decadal Oscillation on annual floods in the rivers of western Canada. J. Am. Water Resour. Assoc. 52 (5), 1031-1045.

Hall, J. et al., 2014. Understanding flood regime changes in Europe: a state of the art assessment. Hydrol. Earth Syst. Sci. 18 (7), 2735-2772.

Hamlet, A.F., Lettenmaier, D.P., 2007. Effects on 20th century warming and climate variability on flood risk in the western U.S. Water Resour. Res. 43, W06427.

Hannaford, J., Buys, G., Stahl, K., Tallaksen, L.M., 2013. The influence of decadal-scale variability on trends in long European streamflow records. Hydrol. Earth Syst. Sci. 17, 2717-2733.

Hannaford, J., Marsh, T.K., 2008. High-flow and flood trends in a network of undisturbed catchments in the UK. Int. J. Climatol. 28, 1325-1338.

Harrigan, S., Murphy, C., Hall, J., Wilby, R.L., Sweeney, S., 2014. Attribution of detected changes in streamflow using multiple working hypotheses. Hydrol. Earth Syst. Sci. 18, 1935-1952.

Hartmann, D.L., 2013. Observations: atmosphere and surface. In: Stocker, T.F. (Ed.) Climate Change 2013: The Physical Science Basis. Contribution of Working Group I to the Fifth Assessment Report of the Intergovernmental Panel on Climate Change. Cambridge University Press, Cambridge, pp. 159-254.

Hirabayashi, Y. et al., 2013. Global flood risk under climate change. Nat. Clim. Change 3, 816-821.

Hosking, J.R.M., 2013. Package “lmom” L-moments R Package.

Hu, Q., Feng, S., Oglesby, R.J., 2011. Variations in North American summer precipitation driven by the Atlantic Multidecadal Oscillation. J. Clim. 24 5555-5570.

Jain, S., Lall, U., 2000. Magnitude and timing of annual maximum floods: trends and large-scale climatic associations for the Blacksmith Fork River. Utah. Water Resour. Res. 36 (12), 3641-3651.

Jain, S., Lall, U., 2001. Floods in a changing climate: does the past represent the future? Water Resour. Res. 37 (12), 3193-3205.

Jonkman, S.N., 2005. Global perspectives on loss of human life caused by floods. Nat. Hazards 34, 154-175.

Klein Tank, A.M.G., Können, G.P., 2003. Trends in indices of daily temperature and precipitation extremes in Europe, 1946-99. J. Clim. 16 (22), 3665-3680.

Knight, J.R., Folland, C.K., Scaife, A.A., 2006. Climate impacts of the Atlantic Multidecadal Oscillation. Geophys. Res. Lett. 33. http://dx.doi.org/10.1029/ 2006 GL026242.

Korhonen, J., Kuusisto, E., 2010. Long-term changes in the discharge regime in Finland. Hydrol. Res. 41 (3-4), 253-268.

Kundzewicz, Z.W. et al., 2005. Trend detection in river flow series: 1. Annual maximum flow. Hydrol. Sci. J. 50, 797-810.

Kundzewicz, Z.W. et al., 2014. Flood risk and climate change: global and regional perspectives. Hydrol. Sci. J. 59, 1-28.

Kunkel, K.E., 2003. North American trends in extreme precipitation. Nat. Hazards 29, 291-305.

Lee, S.Y., Hamlet, A.F., Fitzgerald, C.J., Burges, S.J., 2011. Methodology for developing flood rule curves conditioned on El Niño-Southern Oscillation classification. J. Am. Water Resour. Assoc. 47, 81-92.

Lindström, G., Bergstrom, S., 2004. Runoff trends in Sweden 1807-2002. Hydrol. Sci. J. $49,69-83$.

Lins, H.F., 2012. USGS hydro-climatic data network 2009 (HCDN-2009). US Geol. Surv. Fact Sheet 3047 (4).

Luce, C.H., Holden, Z.A., 2009. Declining annual streamflow distributions in the Pacific Northwest United States, 1948-2006. Geophys. Res. Lett. 36, 6. http://dx. doi.org/10.1029/2009GL039407.

Madsen, H., Lawrence, D., Lang, M., Martinkova, M., Kjeldsen, T.R., 2014. Review of trend analysis and climate change projections of extreme precipitations and floods in Europe. J. Hydrol. 519, 3634-3650.

Mantua, N.J., Hare, S.R., 2002. The Pacific Decadal Oscillation. J. Oceanogr. 58, 35-44.

Marsh, T., 2010. The UK Benchmark Network-Designation, Evolution and Application.

McCabe, G.J., Palecki, M.A., 2006. Multidecadal climate variability of global lands and oceans. Int. J. Climatol. 267, 849-865.

McCabe, G.J., Wolock, D.M., 2008. Joint variability of global runoff and global sea surface temperatures. J. Hydrometeorol. 9 (4), 816-824.
McCullagh, P., Nelder, J.A., 1989. Generalized Linear Models. Chapman and Hall/CRC. Mediero, L. et al., 2015. Identification of coherent flood regions across Europe by using the longest streamflow records. J. Hydrol. 528, 341-360.

Mediero, L., Santillán, D., Garrote, L., Granados, A., 2014. Detection and attribution of trends in magnitude, frequency and timing of floods in Spain. J. Hydrol. 517, 1072-1088.

Merz, B., Vorogushyn, S., Uhlemann, S., Delgado, J., Hundecha, Y., 2012. More efforts and scientific rigour are needed to attribute trends in flood time series. Hydrol. Earth Syst. Sci. 16, 1379-1387.

Milly, P.C.D., Wetherald, R.T., Delworth, T.L., 2002. Increasing risk of great floods in a changing climate. Nature 415, 514-517.

Moberg, A. et al., 2006. Indices for daily temperature and precipitation extremes in Europe analyzed for the period 1901-2000. J. Geophys. Res. Atmos. 111 (D22).

Mudelsee, M., Börngen, M., Tetzlaff, G., 2003. No upward trend in the occurrence of extreme floods in central Europe. Nature 425, 166-169.

Murphy, C., Harrigan, S., Hall, J., Wilby, R.L., 2013. Climate-driven trends in mean and high flows from a network of reference stations in Ireland. Hydrol. Sci. J., 118

Peel, M.C., Finlayson, B.L., McMahon, T.A., 2007. Updated world map of the KöppenGeiger climate classification. Hydrol. Earth Syst. Sci. 11, 1633-1644.

Peterson, T.C. et al., 2013. Monitoring and understanding changes in heat wave, cold waves, floods, and droughts in the United States: State of Knowledge. Bull. Am. Meteorol. Soc. 94, 821-834.

R_Development_Core_Team, 2014. R: A Language and Environment for Statistical Computing. R Foundation for Statistical Computing.

Schmocker-Fackel, P., Naef, F., 2010. More frequent flooding? Changes in flood frequency in Switzerland since 1850. J. Hydrol. 381, 1-8.

Seneviratne, S.I. et al., 2012. Changes in climate extremes and their impacts on the natural physical environment. In: Managing the risks of extreme events and disasters to advance climate change adaptation, pp. 109-230.

Shorthouse, C., Arnell, N., 1999. The effects of climatic variability on spatial characteristics of European river flows. Phys. Chem. Earth B 24, 7-13.

Stahl, K. et al., 2010. Streamflow trends in Europe: evidence from a dataset of nearnatural catchments. Hydrol. Earth Syst. Sci. Discuss. 7, 5769-5804.

Stahl, K., Tallaksen, L.M., Hannaford, J., van Lanen, H.A.J., 2012. Filling the white space on maps of European runoff trends: estimates from a multi-model ensemble. Hydrol. Earth Syst. Sci. 16, 2035-2047.

Sutton, R.T., Dong, B., 2012. Atlantic Ocean influence on a shift in European climate in the 1990s. Nat. Geosci. 5 (11), 788-792.

Trenberth, K.E., 2011. Changes in precipitation with climate change. Clim. Res. 47, $123-138$.

Van den Besselaar, E.J.M., Klein Tank, A.M.G., Buishand, T.A., 2013. Trends in European precipitation extremes over 1951-2010. Int. J. Climatol. 33 (12), 2682-2689.

Veijalainen, N., Lotsari, E., Alho, P., Vehviläinen, B., Käyhkö, J., 2010. National scale assessment of climate change impacts on flooding in Finland. J. Hydrol. 391 (3), 333-350.

Vogel, R.M., Yaindl, C., Walter, M., 2011. Nonstationarity: flood magnification and recurrence reduction factors in the United States. J. Am. Water Resour. Assoc. 47, 464-474.

Ward, P.J., Kummu, M., Lall, U., 2016. Flood frequencies and durations and their response to El Niño Southern Oscillation: Global analysis. J. Hydrol. 539, 358378.

Waylen, P., Woo, M.-K., 1982. Prediction of annual floods generated by mixed processes. Water Resour. Res. 18, 1283-1286.

Whitfield, P.H., 2012. Floods in future climates: a review. J. Flood Risk Manage. 5, 336-365.

Whitfield, P.H. et al., 2012. Hydrologic reference networks I. The status of national reference hydrologic networks for detecting trends and future directions. Hydrol. Sci. J. 57, 1562-1579.

Whitfield, P.H., Moore, R.D., Fleming, S.W., Zawadzki, A., 2010. Pacific Decadal Oscillation and the hydroclimatology of western Canada - review and prospects. Can. Water Resour. J. 35, 1-28.

Wilson, D., Hisdal, H., Lawrence, D., 2010. Has streamflow changed in the Nordic countries? Recent trends and comparisons to hydrological projections. J. Hydrol. 394, 334-346.

Yiou, P., Nogaj, M., 2004. Extreme climate events and weather regimes over the North Atlantic: when and where? Geophys. Res. Lett. 31. http://dx.doi.org/ 10.1029/2003GL019119. 